\title{
Rare $\beta$-Globin Gene Mutations including a de novo Mutation of Hemoglobin Hammersmith in Southern Thailand
}

Korntip Srewaradachpisal, M.Sc. , Wanicha Tepakhan, Ph.D. ${ }^{1}$, Sataron Kanjanaopas, B.Sc. , Chawadee Nopparatana, M.Sc. ${ }^{1}$, Malai Wongchanchailert, M.D. ${ }^{2}$, Chamnong Nopparatana, Ph.D. ${ }^{1}$

'Department of Pathology, Faculty of Medicine, Prince of Songkla University, Hat Yai, Songkhla 90110, Thailand.

2Department of Pediatrics, Faculty of Medicine, Prince of Songkla University, Hat Yai, Songkhla 90110, Thailand.

Received 2 October 2019 • Revised 7 March 2020 • Accepted 13 March 2020 • Published online 15 May 2020

\begin{abstract}
:
Objective: The aim of this study was to characterize unknown $\beta$-globin gene mutations in individuals who attended Songklanagarind Hospital for thalassemia screening and genetic counseling.

Material and Methods: $\beta$-thalassemia mutations in individuals with hemoglobin $(\mathrm{Hb})$ A2 levels $>3.5 \%$ originating from various provinces in southern Thailand were characterized by reverse dot blot hybridization (RDB) and multiplex gappolymerase chain reaction using a panel of 30 allele-specific probes for point mutations and 6 sets of specific primers for large deletions. Mutations which could not be identified by these two methods were further analyzed by direct deoxyribonucleic acid (DNA) sequencing.

Results: Nineteen subjects found to have uncharacterized $\beta$-globin gene mutations were analyzed by direct DNA sequencing. Nine different rare mutations were identified, four of which have not been to date described in Thailand: -30 $(\mathrm{T}>\mathrm{C}$ ), codon 5 (-CT), Hb Monroe (codon 30, $\mathrm{G}>\mathrm{C}$ ) and $\mathrm{Hb}$ Hammersmith (codon 42, $\mathrm{T}>\mathrm{C}$ ). An Hb Hammersmith mutation detected in one subject appeared to be a spontaneous mutation, unrelated to family history. The other five mutations have been reported previously within Thailand, but here they were identified in the southern part of Thailand for the first time: -31 $(A>G)$, codon $15(-T)$, codon $35(C>A)$, codon $95(+A)$ and $\mathrm{Hb}$ Dhonburi (codon 126, $T>G)$. The presence of the mutations was confirmed by RDB.
\end{abstract}

Contact: Chamnong Nopparatana, Ph.D.

Department of Pathology, Faculty of Medicine, Prince of Songkla University,

Hat Yai, Songkhla 90110, Thailand.

E-mail: chamnong.n@psu.ac.th

(c) 2020 JHSMR. Hosting by Prince of Songkla University. All rights reserved.

This is an open access article under the CC BY-NC-ND license

(http://www.jhsmr.org/index.php/jhsmr/about/editorialPolicies\#openAccessPolicy).
J Health Sci Med Res 2020;38(3):221-229 doi: 10.31584/jhsmr.2020741 www.jhsmr.org 
Conclusion: In addition to the already reported $\beta$-globin gene mutations, 9 other different types of mutations were identified. This information should be useful for planning genetic counseling and prenatal diagnosis programs for prevention and control of thalassemia diseases.

Keywords: hemoglobinopathy, rare mutation, southern Thailand, $\beta$-globin gene

\section{Introduction}

$\beta$-Thalassemia ( $\beta$-thal) is a common inherited blood disorder in Thailand. ${ }^{1,2}$ It was estimated that with a population of 63 million in the millennium year 2007, there were about 5,749 infants born each year with severe thalassemia, including 1,017 with homozygous $\alpha^{0}$-thal, 779 with homozygous $\beta$-thal and 3,953 with hemoglobin $(\mathrm{Hb})$ $\mathrm{E} / \beta$-thal disease. ${ }^{3}$ Previous studies have shown that the molecular basis of $\beta$-thal in Thailand is heterogeneous and there are at least 40 known mutations on the $\beta$-globin gene which cause $\beta$-thal disease. The mutations have different frequencies in different parts of the country with various ethnicities. In the south of Thailand, about 30 mutations have been detected. There are seven known common mutations including cod 41/42 (-CTTT) (HBB: c.126_ 129delCTTT), IVS I\#5 (G>C) (HBB: c.92+5G>C), cod 19 (A>G) (HBB: c.59A>G), cod 17 (A>T) (HBB: c.52A>T), IVS I\#1 (G>T) (HBB: c.92+1G>T), -28 (A>G) (HBB: c. -78A>G) and 3.5 kilobase $(\mathrm{kb})$ deletion, which account for about $90.0 \%$ of the cases. ${ }^{4}$ However, because of the diversity of the mutations, unidentified-to-date mutations are occasionally found in routine analysis, identified as rare or unknown mutations. In order to provide an effective thalassemia control program, identification of each unknown mutation should be carried out. Therefore, the objective of this study was to characterize the unknown $\beta$-globin mutations found during the routine test.

\section{Material and Methods}

Ethical approval for the study was obtained from the Human Research Ethics Committee, Faculty of Medicine, Prince of Songkla University (REC: 57-331-05-8). The study subjects were 19 unrelated individuals who had been referred to the Thalassemia Unit of Songklanagarind Hospital, the largest tertiary care center and referral hospital in southern Thailand, for molecular screening of $\beta$-globin mutations. Blood samples were taken from each subject for hematology and hemoglobin analysis to assess their thalassemia status. Hematological data were obtained using an automated blood cell counter (Sysmex XN 3000; Sysmex, Japan). Hemoglobin analysis was performed by either high-performance liquid chromatography (HPLC) [Variant $^{\mathrm{TM}}$; Bio-Rad Laboratories, Hercules, California, the United States of America (USA)] or capillary electrophoresis (CE) (Capillarys 2; Sebia, Lisses, France).

\section{Molecular analysis of $\beta$-globin mutations by reverse} dot blot hybridization and multiplex gap-polymerase chain reaction

Genomic deoxyribonucleic acid (DNA) was extracted from the blood samples with a genomic DNA Mini Kit (Geneaid, Taiwan). The yield and purity of the DNA were determined by gel electrophoresis and spectrophotometer. The DNA samples were screened for common or prevalent $\beta$-globin mutations by reverse dot blot hybridization (RDB) and multiplex gap-polymerase chain reaction (PCR) using a panel of 30 allele-specific probes for point mutations and 6 sets of specific primers for large deletions. ${ }^{5,6} \mathrm{~A}$ total of 19 samples which were found to have unknown $\beta$ globin mutations were subjected to direct DNA sequencing using an automated DNA sequencing system (ABI 3500; $\mathrm{ABI}, \mathrm{USA})$. Two regions of the $\beta$-globin gene of the samples were analyzed by two sets of primers; R1 (5'TCCCCAGTTAACCTCCTATT-3') and R2 (5' 
TCATTCGTCTGTTTCCCATTCTAAAC-3') designed for initial site, exon I, intron I and exon II; and R3 (5'-GTGTACACATATTGACCAAATC-3') and R4: (5'-CAGATTCCGGGTCACTGTG-3') designed for intron II, exon III and polyA site. The presence of identified mutations was confirmed by RDB.

\section{Results}

Following DNA sequence analysis of the PCRamplified fragments, 9 different mutations were identified in the 19 unrelated subjects. Three of these mutations were $\beta^{+}$-thal involving two promoter mutations: 2 subjects with -30 (T>C) (HBB: c. $-80 T>C$ ) and 2 subjects with -31 $(A>G)$ (HBB: c. $-81 A>G)$; and one missense mutation: 3 subjects with $\mathrm{Hb}$ Dhonburi [ $\operatorname{cod} 126,(T>G), H B B$ : c.380T>G]; while the other five mutations were $\beta^{0}$-thal: three frameshift mutations, 1 subject with cod 5 (-CT) (HBB: c.17_18delCT), 5 subjects with cod 15 (-T) (HBB: c.46delT), and 1 subject with cod $95(+A) / H b E(H B B:$ c.287_288insA; 79G>A); one nonsense mutation: 2 subjects with cod $35(\mathrm{C}>\mathrm{A})$ (HBB: c.108C>A); and one missense mutation: 2 subjects with $\mathrm{Hb}$ Monroe $[\operatorname{cod} 30(\mathrm{G}>\mathrm{C})$, HBB: c.92G>C]. Also, one mutation causing an unstable $\mathrm{Hb}$ variant was found in 1 subject with $\mathrm{Hb}$ Hammersmith [cod 42 (T>C), HBB:c.128T>C] (Table 1). Eighteen subjects were heterozygous for b-thal alleles. One subject was compound heterozygous for $\beta$-thal and $\mathrm{HbE}(\operatorname{cod} 95(+\mathrm{A}) / \mathrm{Hb} \mathrm{E})$.

Among the 18 subjects with heterozygous $\beta$-thal, 8 subjects including 3 subjects with $\operatorname{cod} 15(-\mathrm{T}), 3$ subjects with $\mathrm{Hb}$ Dhonburi, 1 subject with $-30(\mathrm{~T}>\mathrm{C})$ and 1 subject with $-31(A>G)$ showed no clinical phenotype, whereas 8 subjects who were pregnant at the time their blood was obtained had mild anemia, including 2 subjects with cod $15(-T)$, 1 subject with $-30(T>C)$, 1 subject with $-31(A>G), 1$ subject with cod $5(-C T), 1$ subject with $\mathrm{Hb}$ Monroe, and 2 subjects with cod $35(\mathrm{C}>\mathrm{A})$. These could have been complications relating to their pregnancies. The other 2 non-pregnant subjects had moderate to severe anemia, including 1 subject with $\mathrm{Hb}$ Monroe and 1 subject with $\mathrm{Hb}$ Hammersmith. A subject with compound heterozygous $\beta$-thal (cod $95(+\mathrm{A}) / \mathrm{Hb} \mathrm{E})$ had moderate anemia as shown in Table 1.

Sequencing chromatograms of the family with $\mathrm{Hb}$ Hammersmith are shown in Figure 1. The studies indicated that only the proband carried the mutation [cod $42(T>C)$ ]. The possibility of non-paternity in this family was tested by restriction fragment length polymorphism typing of variable-number tandem repeat loci D1S80. ${ }^{7}$ The result of the paternity test are shown in Figure 2.

\section{Discussion}

In this study, we report nine different $\beta$-globin mutations, including $-30(T>C),-31(A>G)$, cod $126(T>G)$, $\operatorname{cod} 5(-\mathrm{CT})$, cod $15(-\mathrm{T})$, cod $95(+\mathrm{A})$, cod $35(\mathrm{C}>\mathrm{A}), \mathrm{Hb}$ Monroe [cod $30(\mathrm{G}>\mathrm{C})$ ], and $\mathrm{Hb}$ Hammersmith [cod 42 $(T>C)]$ found in thalassemia patients in southern Thailand. Among these, four mutations, $-30(\mathrm{~T}>\mathrm{C})$, cod $5(-\mathrm{CT}), \mathrm{Hb}$ Monroe, and $\mathrm{Hb}$ Hammersmith, were firstly identified in Thailand

The $-30(T>C)$ mutation is located in the TATA box region leading to reduced transcription factor binding efficiency, ultimately resulting in decreased $\beta$-globin gene transcription and manifesting as $\beta^{+}$-thal. This mutation was described originally in a Chinese male at prenatal diagnosis. ${ }^{8}$ There have been no other reports of this mutation until our two subjects. It is noteworthy that they had borderline mean corpuscular volume (MCV) values, 80.2 and $80.8 \mathrm{fL}$, suggesting that other $-30(\mathrm{C}>\mathrm{T})$ carriers might have been misdiagnosed at thalassemia screenings using red blood cell indices with MCV cut-off values $<80 \mathrm{fL} .{ }^{9}$ However, the mean corpuscular hemoglobin values were lower than normal (<27 pg) (Table 1), this should be helpful in the screening for this mutation. 


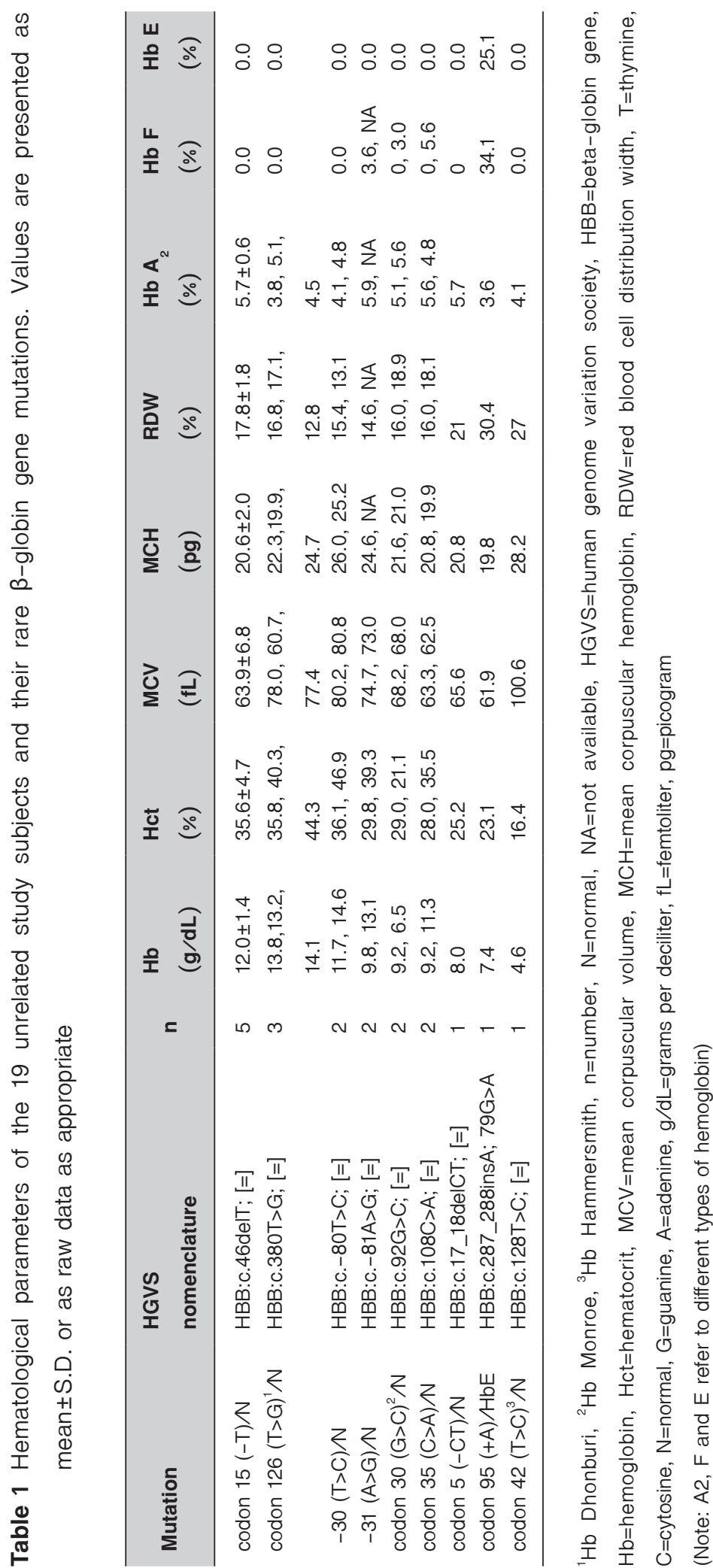




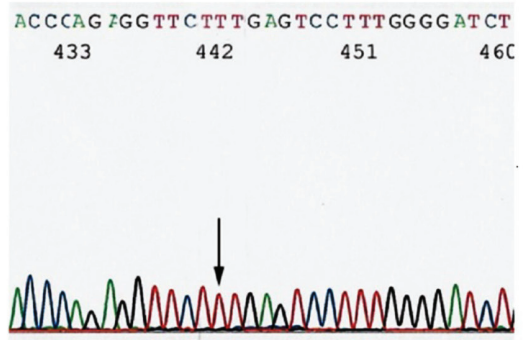

A
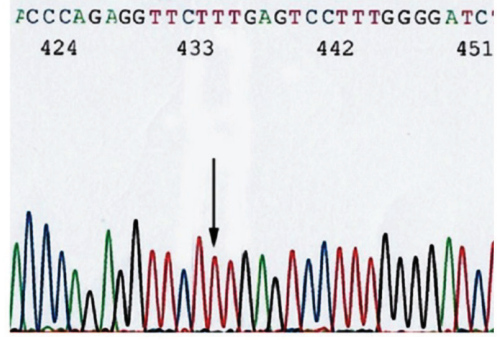

B

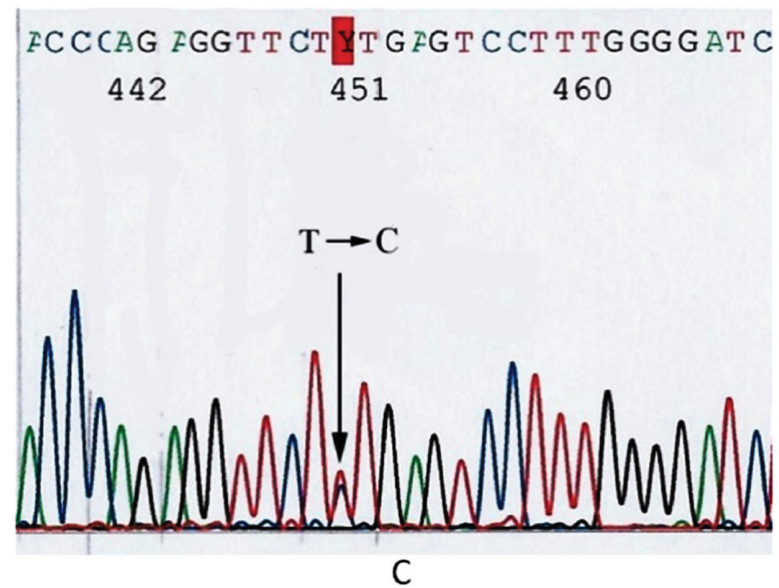

Figure 1 Sequencing chromatograms of the family with $\mathrm{Hb}$ Hammersmith: A, father, B, mother, and C, 6-year-old female patient. Arrows indicate the location of the mutation site.

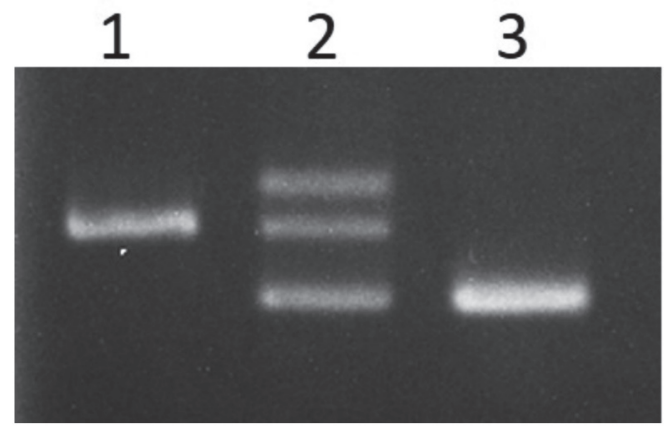

Figure 2 Agarose gel electrophoresis of VNTR loci D1S80 in the family of the patient with de novo Hb Hammersmith: Lane 1 shows the mother's allele, Lane 3 shows the father's allele, and Lane 2 shows the patient's allele, as she received alleles from her mother and father. 
The cod 5 (-CT) mutation, a frameshift mutation of Mediterranean origin, results in a termination of translation at $\operatorname{cod} 21$, causing $\beta^{0}$-thal. This mutation was observed originally in a Greek patient with transfusiondependent anemia and has also been reported in Western and South Asian populations, specifically in Asian Indian, Iranian and Arab populations. ${ }^{10-13}$ Recently, it was also documented in Yunnan in Southwest China. ${ }^{14}$

$\mathrm{Hb}$ Monroe is an $\mathrm{Hb}$ variant resulting from a nucleotide substitution from $\mathrm{G}$ to $\mathrm{C}$ at a splice site area of cod 30. This mutation leads to the inhibition of normal splicing, causing $\beta^{0}$-thal. ${ }^{15}$ The first description of this $\mathrm{Hb}$ variant was in an African-American girl in the USA, which she co-inherited with the -29 ( $A>G)$ mutation. ${ }^{16}$ The mutation has also been reported in Tunisian, Lebanese, United Arab Emirates, Asian Indian and Iranian populations. ${ }^{11-13}$ The clinical phenotype of the heterozygote is mild anemia, although in combination with other mutations it can present as transfusion-dependent $\beta$-thal major. ${ }^{16,17}$ In this study, we also found one of two cases of the $\mathrm{Hb}$ Monroe heterozygote presented with severe anemia (Table 1), possibly involving other causes of anemia such as iron deficiency, which is highly prevalent in Thailand. ${ }^{18}$

Another unstable $\beta$-chain variant found by this study for the first time in Thailand was $\mathrm{Hb}$ Hammersmith. This $\mathrm{Hb}$ variant is caused by a $\mathrm{T}$ to $\mathrm{C}$ substitution in the second base of cod 42 resulting in an amino acid change from phenylalanine to serine. This replacement reduces the strength of the bond between heme and globin, causing denaturation and precipitation of the hemoglobin molecule on the RBC membrane which results in RBC destruction. Since this $\mathrm{Hb}$ is co-separated with $\mathrm{Hb} A$, it is undetectable on routine $\mathrm{Hb}$ analysis by CE. However, increasing $\mathrm{Hb} \mathrm{A}_{2}$ levels indicates a $\beta$-thal carrier and further DNA analysis is needed to detect this mutation. $\mathrm{Hb}$ Hammersmith was first described in two unrelated children with hemolytic anemia in Britain. ${ }^{19}$ Many studies have shown that this mutation usually presents as an autosomal dominant resulting in severe hemolytic anemia, which was also found in the patient of this study. The blood smear of this patient showed hypochromic microcytic RBCs with ovalocytes, rare target cells and a few schistocytes. In addition, basophilic stippling and Howell-Jolly bodies were seen. $\mathrm{Hb}$ Hammersmith has been found in several ethnic backgrounds to date, including English, Tunisian, Japanese, Caucasian, Indian, Chinese, African, American and Brazilian. ${ }^{20-25}$ Interestingly, all of the known cases to date have been female, as was the patient in this study. However, two recent studies have reported this mutation in a Korean male and a Chinese male with hemolytic anemia. $^{26,27}$ Still, the higher frequency of female patients than male is not yet understood and further investigations are needed to explore the mechanism and molecular pathogenesis of this mutation. Many studies have shown that $\mathrm{Hb}$ Hammersmith in most patients is a spontaneous mutation $^{20-24,26,27}$, as it was in the patient in this study (Figure 1).

In addition, we identified five mutations reported previously in Thailand including, $-31(\mathrm{~A}>\mathrm{G})$, cod $15(-\mathrm{T})$, cod $35(\mathrm{C}>\mathrm{A})$, cod $95(+\mathrm{A})$ and Hb Dhonburi [cod 126 $(T>G)]$ found in southern Thailand for the first time. The -31 (A>G) mutation, a point mutation in the TATA box of the $\beta$-globin promoter causing $\beta^{+}$-thal, was reported firstly homozygously in a Japanese patient, and was subsequently found to have a high incidence in Japan. ${ }^{28}$ In Thailand, carriers of this mutation have been found in many parts of the country, including the North and Northeast. ${ }^{29,30}$ Another $\beta^{+}$-thal mutation was found in this study, $\mathrm{Hb}$ Dhonburi, also known as $\mathrm{Hb}$ Neapolis. This variant is caused by a $\mathrm{T}$ to G substitution at cod 126 resulting in the changing of valine to glycine and activation of a cryptic splice site in the exon. This induces instability of the $\mathrm{Hb}$ molecule but no change in its oxygen binding properties. ${ }^{31}$ It is noteworthy that $\mathrm{Hb}$ Dhonburi has been found to be a co-migrant with $\mathrm{Hb}$ A from CE and HPLC analysis. ${ }^{32}$ It could easily be missed in routine 
analysis unless DNA analysis is performed. Hb Dhonburi was discovered originally in a Thai male who presented as the $\beta$-thal intermedia phenotype because of a combination with $\beta^{0}$-thal. ${ }^{31} \mathrm{Hb}$ Dhonburi has been subsequently found in various populations including northeastern and central Thais, and in Italy and Iran..$^{30,32,33}$ In this study we also identified three $\beta^{0}$-thal mutations described previously in Thailand, cod $15(-\mathrm{T})$, cod $95(+\mathrm{A})$ and $\operatorname{cod} 35(\mathrm{C}>\mathrm{A})$. The frameshift mutations at cod $15(-\mathrm{T})$ and cod $95(+\mathrm{A})$ lead to a premature termination codon at cod 18 and 101 , respectively. Cod $15(-\mathrm{T})$ was identified for the first time in a Malaysian family in combination with the polyA (-AT) (HBB: c.[ $\left.\left.{ }^{\star} 109 \_{ }^{*} 110 d e l A T\right]\right)$ mutation causing the $\beta$-thal major phenotype. Since then, cod $15(-\mathrm{T})$ has been documented occaHBBsionally in Asia, including the Thai, Bangladeshi, Indonesian and Indian populations. ${ }^{34-37}$ Initially, cod 95 (+A) was found in combination with $\mathrm{Hb} E(\mathrm{HBB}$ : c.79G $>\mathrm{A})$ in a patient who presented as a $\beta$-thal intermedia phenotype from the central part of Thailand, and it has also recently been reported in northern Thailand. ${ }^{34}$ In this study, we also observed this mutation co-inherited with $\mathrm{Hb} \mathrm{E}$ in one patient with moderate anemia (Table 1). In addition to Thailand, this mutation has been frequently observed in Vietnamese individuals, in either the heterozygous stage or compound heterozygous with $\mathrm{Hb} \mathrm{E}$, known as the "Vietnamese mutation". ${ }^{38}$ The nonsense mutation at cod 35 is caused by a C to A substitution which creates a premature stop codon (TAA) at cod 35. Originally, this mutation was discovered in combination with $\mathrm{Hb} E$ in a Thai patient from central Thailand, and has been reported only rarely. ${ }^{39}$ Recently, the homozygous cod $35(\mathrm{C}>\mathrm{A})$ was identified in a Moroccan girl who presented with a thalassemia intermedia phenotype. ${ }^{40}$

\section{Conclusion}

The results of this study, in combination with other studies, improves the knowledge of the spectrum of thalassemia mutations in Thailand, which will be useful for planning genetic counseling and prenatal diagnosis programs for prevention and control of the disease.

\section{Acknowledgement}

The authors thank Mr. David Leslie Patterson of the International Affairs Office of the Faculty of Medicine, Prince of Songkla University for editing the English in the manuscript.

\section{Funding sources}

This study was supported by research grants from the Faculty of Medicine, Prince of Songkla University (REC. 52-057-05-2-3 and REC. 57-331-05-8).

\section{Conflict of interest}

There are no potential conflicts of interest to declare.

\section{References}

1. Fucharoen S, Winichagoon P. Haemoglobinopathies in Southeast Asia. Indian J Med Res 2011;134:498-506.

2. Thein SL, Winichagoon P, Hesketh C, Best S, Fucharoen S, Wasi $\mathrm{P}$, et al. The molecular basis of beta-thalassemia in Thailand: application to prenatal diagnosis. Am J Hum Genet 1990;47:369-75.

3. Modell B. Epidemiological estimates for haemoglobin disorders: WHO South East Asian Region by Country. Bull World Health Organ [serial on the Internet]. 2007 [cited 2019 Oct 1]. Available from: http://www.modell-almanac.net/world. sear.pdf

4. Nopparatana C, Panich V, Saechan V, Sriroongrueng V, Nopparatana C, Rungjeadpha J, et al. The spectrum of betathalassemia mutations in southern Thailand. Southeast Asian J Trop Med Public Health 1995;26(Suppl 1):S229-34.

5. Sutcharitchan $P$, Saiki R, Fucharoen $S$, Winichagoon $P$, Erlich H, Embury SH. Reverse dot-blot detection of Thai betathalassaemia mutations. $\mathrm{Br} \mathrm{J}$ Haematol 1995;90:809-16.

6. Fucharoen S, Pengjam Y, Surapot S, Fucharoen G, 
Sanchaisuriya K. Molecular and hematological characterization of HPFH-6/Indian deletion-inversion Ggamma (Agammadeltabeta)0-thalassemia and Ggamma (Agammadeltabeta)0-thalassemia/HbE in Thai patients. Am J Hematol 2002;71:109-13.

7. Budowle B, Chakraborty R, Glusti AM, Eisenberg AJ, Allen RC. Analysis of VNTR Locus D1S80 by the PCR followed by high-resolution PAGE. Am J Hum Genet 1991;48:137-44.

8. Cai SP, Zhang JZ, Doherty M, Kan YW. A new TATA box mutation detected at prenatal diagnosis for beta-thalassemia. Am J Hum Genet 1989;45:112-4.

9. Sanchaisuriya K, Fucharoen S, Fucharoen G, Ratanasiri T, Sanchaisuriya $P$, Changtrakul $Y$, et al. A reliable screening protocol for thalassemia and hemoglobinopathies in pregnancy: an alternative approach to electronic blood cell counting. Am J Clin Pathol 2005;123:113-8.

10. Kollia P, Gonzalez-Redondo JM, Stoming TA, Loukopoulos D, Politis C, Huisman TH. Frameshift codon 5 [Fsc-5 (-CT)] thalassemia; a novel mutation detected in a Greek patient. Hemoglobin 1989;13:597-604.

11. Agarwal S, Hattori $Y$, Agarwal SS. Rare beta-thalassemia mutations in Asian Indians. Am J Hematol 2000;65:322-3.

12. Akhavan-Niaki $H$, Derakhshandeh-Peykar P, Banihashemi A, Mostafazadeh A, Asghari B, Ahmadifard MR, et al. A comprehensive molecular characterization of beta-thalassemia in a highly heterogeneous population. Blood Cells Mol Dis 2011;47:29-32.

13. Zahed $L$. The Spectrum of beta-Thalassemia mutations in the Arab Populations. J Biomed Biotechnol 2001;1:129-32.

14. Zhang J, Zhu BS, He J, Zeng XH, Su J, Xu XH, et al. The spectrum of $\alpha$ - and $\beta$-thalassemia mutations in Yunnan province of Southwestern China. Hemoglobin 2012;36:46473.

15. Vidaud M, Gattoni R, Stevenin J, Vidaud D, Amselem S, Chibani J, et al. A 5 ' splice-region G----C mutation in exon 1 of the human beta-globin gene inhibits pre-mRNA splicing: a mechanism for beta+-thalassemia. Proc Natl Acad Sci U S A 1989;86:1041-5.

16. Gonzalez-Redondo JM, Stoming TA, Lanclos KD, Gu YC, Kutlar A, Kutlar F, et al. Clinical and genetic heterogeneity in black patients with homozygous beta-thalassemia from the southeastern United States. Blood 1988;72:1007-14.

17. Hamid M, Shariati G, Saberi A, Kaikhaei B, Galehdari H,
Mohammadi-Anaei M. Identification of IVS-I ( -1$)(G>C)$ or $\mathrm{Hb}$ Monroe as a report on the beta-globin gene with a betathalassemia minor phenotype in south of Iran. Arch Iran Med 2013;16:563-4.

18. Piammongkol S, Chongsuvivatwong V, Williams G, Pornpatkul $M$. The prevalence and determinants of iron deficiency anemia in rural Thai-Muslim pregnant women in Pattani province. Southeast Asian J Trop Med Public Health 2006;37: 553-8.

19. Dacie JV, Shinton NK, Gaffney PJ Jr, Lehmann H. Haemoglobin Hammersmith (beta-42 (CDI) Phe replaced by ser). Nature 1967;216:663-5.

20. Akiyama M, Murayama S, Yokoi K, Yanagisawa T, Hattori $Y$, Yamashiro $Y$, et al. Hemoglobin Hammersmith [beta 42(CD1) Phe --> Ser] causing severe hemolytic anemia in a Japanese girl. Pediatr Blood Cancer 2006;47:839-41.

21. Rahbar S, Feagler RJ, Beutler E. Hemoglobin Hammersmith (beta 42 (CD1) Phe replaced by Ser) associated with severe hemolytic anemia. Hemoglobin 1981;5:97-105.

22. Cunningham TA, Baker F, Kobrinsky NL, Cepreganova B, Baysal E, Wilson JB, et al. The unstable Hb Hammersmith or alpha2 beta2(42)(CD1)Phe----Ser observed in an Indian child; identification by HPLC and by sequence analysis of amplified DNA. Hemoglobin 1992;16:19-25.

23. Rahbar S, Bennetts GA, Ettinger LJ. Hemoglobin Hammersmith as the cause of severe hemolytic anemia in a Chinese girl. Am J Pediatr Hematol Oncol 1986;8:13-7.

24. Tuohy AM, McKie VC, Sabio H, Kutlar F, Kutlar A, Wilson JB. $\mathrm{Hb}$ Hammersmith [beta 42(CD1) Phe-->Ser]: occurrence as a de novo mutation in black monozygotic twins with multiple congenital anomalies. J Pediatr Hematol Oncol 1998;20:563-6.

25. Sonati MF, Kimura EM, Abreu CF, Oliveira DM, Pinheiro VR, Costa FF. Hemoglobin Hammersmith [beta 42 (CD1) Phe --> Ser] in a Brazilian girl with congenital Heinz body hemolytic anemia. Pediatr Blood Cancer 2006;47:855-6.

26. Park S, Kang HJ, Cho SI, Kim SY, Seong MW, Park SS. A case report of a male patient with $\mathrm{Hb}$ Hammersmith $[\beta 42$ (CD1)Phe-->Ser, TTT>TCT]. Hemoglobin 2012;36:161-5.

27. Li R, Wang $T$, Xie XM, Li DZ. Case report: prenatal diagnosis of Hb Hammersmith [B42(CD1)Phe-->Ser; HBB: c.128T > C] in a family with an adult male patient. Hemoglobin 2014;38: 142-5. 
28. Takihara $Y$, Nakamura T, Yamada H, Takagi Y, Fukumaki YA. A novel mutation in the TATA box in a Japanese patient with beta+-thalassemia. Blood 1986;67:547-50.

29. Sirichotiyakul S, Saetung R, Sanguansermsri T. Analysis of beta-thalassemia mutations in northern Thailand using an automated fluorescence DNA sequencing technique. Hemoglobin 2003;27:89-95.

30. Yamsri S, Singha K, Prajantasen T, Taweenan W, Fucharoen $G$, Sanchaisuriya $K$, et al. A large cohort of $\beta(+)$-thalassemia in Thailand: molecular, hematological and diagnostic considerations. Blood Cells Mol Dis 201;54:164-9.

31. Bardakdjian-Michau J, Fucharoen S, Delanoe-Garin J, Kister J, Lacombe C, Winichagoon P, et al. Hemoglobin Dhonburi alpha 2 beta $2126(\mathrm{H} 4)$ Val----Gly: a new unstable beta variant producing a beta-thalassemia intermedia phenotype in association with beta zero-thalassemia. Am J Hematol 1990;35:96-9.

32. Viprakasit V, Chinchang W. Two independent origins of $\mathrm{Hb}$ Dhonburi (Neapolis) [beta $126(\mathrm{H} 4)$ Val-->Gly]: an electrophoretically silent hemoglobin variant. Clin Chim Acta 2007; 376:179-83.

33. Moghimi B, Yavarian M, Oberkanins C, Amini S, Khatami S, Rouhi S, et al. Hb Dhonburi (Neapolis) [beta126(H4)Val-->Gly] identified in a family from northern Iran. Hemoglobin 2004; 28:353-6.

34. Winichagoon $P$, Fucharoen $S$, Wilairat $P$, Chihara K, Fukumaki $Y$, Wasi $P$. Identification of five rare mutations including a novel frameshift mutation causing beta zerothalassemia in Thai patients with beta zero-thalassemia/hemoglobin $E$ disease. Biochim Biophys Acta 1992;1139:280-6.

35. Hasan KN, Khaleque MA, Majumder AK, Rahman MM, Akhteruzzaman S. Identification of compound heterozygosity for a rare beta-globin gene mutation, codon $15(-\mathrm{T})$ with a common mutation IVS1-5 (G>C) by direct sequencing in a Bangladeshi patient. Biores comm 2016;2:245-8.

36. Hernanda PY, Tursilowati L, Arkesteijn SG, Ugrasena ID, Larasati MC, Soeatmadji SM, et al. Towards a prevention program for $\beta$-thalassemia. The molecular spectrum in East Java, Indonesia. Hemoglobin 2012;36:1-6.

37. Gajra B, Bandyopadhyay D, Chakrabarti S, Sengupta B, De $\mathrm{M}$, Shaji RV, et al. Thalassemia beta0 due to an identical frameshift mutation, codon $15(-\mathrm{T})$ in both parents. Am J Hematol 2004;75:117.

38. Doro MG, Casu G, Frogheri L, Persico I, Triet LPM, Hoa PTT, et al. Molecular characterization of $\beta$-Thalassemia mutations in Central Vietnam. Hemoglobin 2017;41:96-9.

39. Boonyawat B, Monsereenusorn C, Traivaree C. Molecular analysis of beta-globin gene mutations among Thai betathalassemia children: results from a single center study. Appl Clin Genet 2014;7:253-8.

40. Girard JM, Drevin G, Brasme JF, Pissard S, Reynier P, Simard $\mathrm{G}$, et al. Clinical and biological specificity of beta-thalassemia intermedia: a case report. Ann Biol Clin (Paris) 2016;74:68892. 